\title{
43982 - LOW DOSE ALPHA 2 ANTAGONIST ACTION ON RAT OPIOID ANALGESIA AND TOLERANCE
}

\author{
Brian Milne, Queen's University, Kingston, ON, Canada; \\ Khem Jhamandas, Queen's University; \\ Maaja Sutak, Queen's University;
}

INTRODUCTION: Ultra-low doses of opioid receptor antagonists paradoxically augment morphine antinociception and block tolerance. Studies have shown that opioid receptors form complexes with alpha 2 receptors and interact functionally with these receptors. Using the rat spinal analgesia model, we examined whether ultra-low doses of antagonists for alpha 2 receptors can influence morphine-induced acute antinociception and tolerance.

METHODS: After Animal Care Committee approval, rats were implanted with intrathecal catheters under halothane anesthesia. The effects of intrathecal morphine or its combination with the antagonists were tested using the tailflick and paw pressure tests. Tolerance was induced by three serial injections of intrathecal morphine (15ug) delivered at 90 minute intervals. The degree of tolerance was assessed by the decrease in level of the antinociceptive response and the loss of agonist potency, as reflected by an increase in the morphine ED50 values obtained 24 hours post treatment. The statistical significance of drug treatments was assessed by using a one-way ANOVA followed by Newman-Keuls post hoc test.

RESULTS: Intrathecal morphine (15ug) produced a maximal antinociceptive effect in both the tailflick and paw pressure test, a response that peaked at 30 minutes and terminated at 90 minutes. Its combination with intrathecal antagonists, yohimbine $(0.02 \mathrm{ng})$, idazoxan $(0.02 \mathrm{ng})$ or mirtazapine $(0.02 \mathrm{ng})$, at a dose that did not produce alpha 2 receptor agonist (clonidine) blockade, very markedly extended the morphine effect, the antinociception persisting significantly above the pre-drug baseline value at 270 minutes post injection $(\mathrm{p}<0.01)$. Repeated morphine injections $(15 \mathrm{ugx} 3)$ reduced the level of the antinociceptive response to $20 \%$ of its original value and produced a 3-5 fold increase in the agonist ED 50 value $(\mathrm{p}<0.001)$. However, similar injections of morphine in combination with the three alpha 2 antagonists not only prevented the decline of antinociception but also abolished the increase in morphine ED50 values, reflecting inhibition of tolerance to the agonist action. Comparable injection of morphine with saline (control) did not prevent the loss of morphine effect. DISCUSSION: This study shows that ultra-low doses of alpha 2 antagonists, well below those producing an alpha 2 receptor blockade, significantly augment acute morphine antinociception and inhibit the loss of potency that is indicative of tolerance to repeated opioid agonist exposure. The opioid receptors that form complexes with alpha 2 receptors may signal paradoxical excitatory responses that oppose the analgesic action of morphine. Blockade of such responses due to action of ultra-low doses of antagonists on the alpha 2 component of the receptor complex thus may allow unhindered expression of morphine effects. Ultra-low dose alpha 2 receptor antagonists could be useful adjuncts to opioid therapy in the management of clinical pain. 